\title{
Comparison of High Frequency Detailed Generator Models for Partial Discharge Localization
}

\section{S. M. Hassan Hosseini ${ }^{\dagger}$ and S. M. Hosseini Bafghi*}

\begin{abstract}
This paper presents partial discharge localization in stator winding of generators using multi-conductor transmission line (MTL) and RLC ladder network models. The high-voltage (HV) winding of a $6 \mathrm{kV} / 250 \mathrm{~kW}$ generator has been modeled by MATLAB software. The simulation results of the MTL and the RLC ladder network models have been evaluated with the measurements results in the frequency domain by applying of the Pearson's correlation coefficients. Two PD generated calibrator signals in $\mathrm{kHz}$ and $\mathrm{MHz}$ frequency range were injected into different points of generator winding and the signals simulated/measured at the both ends of the winding. For partial discharge localization in stator winding of generators is necessary to calculate the frequency spectrum of the PD current signals and then estimate the poles of the system from the calculated frequency spectrum. Finally, the location of PD can be estimated. This theory applied for the above generator and the simulation/measured results show the good correlation for PD Location for RLC ladder network and MTL models in the frequency range of $\mathrm{kHz}(10 \mathrm{kHz}<\mathrm{f}<1 \mathrm{MHz})$ and $\mathrm{MHz}(1 \mathrm{MHz}<\mathrm{f}<5 \mathrm{MHz})$ respectively.
\end{abstract}

Keywords: Generators, Partial discharge, Pearson's correlation coefficients, Multi-conductor transmission line model, RLC ladder network model.

\section{Introduction}

Generators are considered to be one of the essential and costly equipment's of power system. Identifying insulation faults in the best possible time prevents the appearance of irreparable damages. Partial discharge (PD) is one of the most important insulation faults. The first step in the study of partial discharge is precise modeling of transformer winding in high frequencies. In this paper two detailed RLC ladder network and MTL Models have been applied for partial discharge studies. The validity of frequency rang of this two models are different. The fundamental elements of the ladder network model are the lumped R, L and C elements and the frequency limitation for the validity of this model is in the range of a few hundred $\mathrm{kHz}$. The fundamental elements of MTL model are distributed parameters. The model accuracy will be expanded over $\mathrm{MHz}$ frequency range. The published works on the machines is more focused on the RLC ladder network model in past [1-6]. While the published works on MTL modeling is mostly concentrated on modeling of electrical rotating machines and also on only the homogenous transformer windings ignoring the frequency dependency of the winding insulation parameters [7-12]. This paper

$\dagger$ Corresponding Author: Dept. of Electrical Engineering, South Tehran Branch, Islamic Azad University, Tehran, Iran.

(Smhh110@azad.ac.ir)

* Dept. of Electrical Engineering, South Tehran Branch, Islamic Azad University, Tehran, Iran. (mojtaba.hoosiny@gmail.com)

Received: April 14, 2014; Accepted: February 13, 2015 compares the two well-known MTL and RLC ladder network models and used these models for PD studies in high frequency range $10 \mathrm{kHz}<\mathrm{f}<5 \mathrm{MHz}$.

\section{MTL Model}

MTL theory deals with a network of $\mathrm{N}$ conductors coupled all together, characterized by its inductance matrix [L], and capacitance matrix [C]. In the MTL model, windings parameters are considered as distributed parameter and winding behavior is described by transmission line equations. MTL model for turns of one coil is depicted in the Fig. 1 [13].

For developing the model a single turn is considered as the basic element of analysis. Fig. 1 shows an electrical machine winding with three turns in series connection. In this figure, $Z_{r}$ is the impedance for representing the

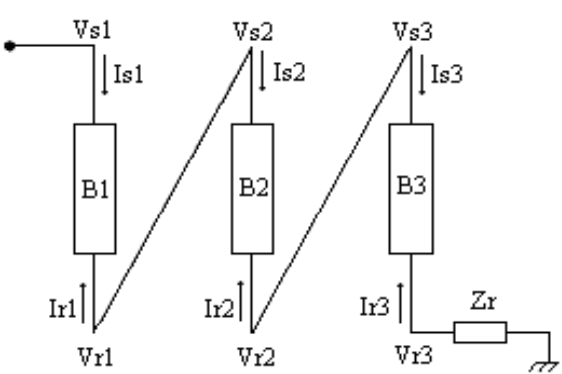

Fig. 1. Winding model with three turns in series connection 
terminal conditions, short and open circuit. The voltage $\mathrm{V}_{\mathrm{s} 1}$ is the surge at the beginning of the winding.

Surge impedances and coefficient of propagation can be estimated of the following Eqs. [7-10].

$$
\begin{gathered}
Z_{i}=\frac{1}{v_{s}\left[c_{0}^{i}+c_{1}^{i}+2 k\left\{1-\cos \left(\frac{\omega a}{v_{s}}\right)\right\}\right]} \\
\gamma=\frac{1}{v_{s} d} \sqrt{\frac{\omega}{2 \sigma \mu}}+\frac{\omega \tan \delta}{2 v_{s}}+\frac{j \omega}{v_{s}}
\end{gathered}
$$

where

$k$ : inter-turn capacitance, $a$ : turns average length $d$ : disks gap, $v_{s}$ : velocity

The first and second terms in the (2) are representing the skin effect and the dielectric losses respectively. $\sigma, \mu$ and $d$ are the conductivity, permeability and the winding coils gap respectively. The details of modeling and the parameters estimation for an inhomogeneous winding (realizing frequency dependent parameters) are discussed in [10].

\subsection{PD Analyses for MTL model}

According to the Fig. 1 we have these telegraphs equations:

$$
\begin{gathered}
\frac{\partial V_{t}}{\partial x}=-L\left(\frac{\partial I_{t}}{\partial t}\right) \\
\frac{\partial I_{t}}{\partial t}=-C\left(\frac{\partial V_{t}}{\partial x}\right)+C_{0} \frac{\partial E_{0}}{\partial t}
\end{gathered}
$$

in Eqs. (3) and (4), $V_{t}$ and $I_{t}$ are the voltage and current vectors. The order is equal to the number of turns in a coil. $L$ and $C$ are square matrices of the inductances and capacitances in the coil while $E_{o}$ and $C_{o}$ denotes the excitation function and capacitance from one turn to the static plate. To study the PD phenomena the excitation function don't exist so in the (4):

$$
\frac{\partial E_{0}}{\partial t}=0
$$

By solve the Eqs. (3) and (4) and by insertion of (5), one can obtain following equations:

$$
\begin{gathered}
V_{i}(x)=A_{i} \exp (-\Gamma(\omega) x)+B_{i} \exp (\Gamma(\omega) x) \\
I_{i}(x)=\frac{1}{z_{i}}\left[A_{i} \exp (-\Gamma(\omega) x)-B_{i} \exp (\Gamma(\omega) x)\right]
\end{gathered}
$$

Eqs. (6) and (7) are $2 n$ equation and contain $2 n$ undefined parameters $\left(A_{i}\right.$ and $\left.B_{i}\right)$. By using the terminal conditions we have:

$$
\begin{aligned}
I r_{1} & =-I s_{2} \quad I r_{2}=-I s_{3} \quad V r_{1}=V s_{2} V r 2=V s_{3} \\
\text { and } \quad-I r_{3} & =V r_{3} / Z r
\end{aligned}
$$

$2 n-2$ equations are available. For two other equation can be simulated by a capacitance $C_{B}$ connected at the line-end. Then,

$$
I_{(s 1)}=-j \omega c_{B} v_{(s 1)}
$$

if the neutral end is at earth potential,

$$
V_{r(N)}=0
$$

If a PD current pulse $I_{P D}$ is injected into the $\mathrm{k}^{\text {th }}$ turn of the winding, (8) is modified when $i=k-1$ :

$$
I_{s}(k)=I_{r}(k-1)+I_{P D}
$$

With applying Eqs. (8) to (11) in Eqs. (6) and (7), the coefficients $A_{i}$ and $B_{i}$ have been calculated and then the current due to PD pulse can be calculated in the generator terminals.

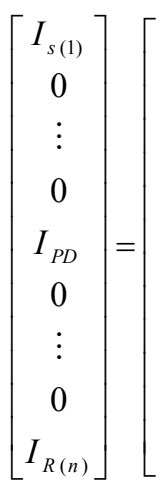

$$
\left[\begin{array}{c}
V_{s(1)} \\
V_{s(2)} \\
\vdots \\
\vdots \\
V_{s(k)} \\
\vdots \\
\vdots \\
V_{s(n)} \\
V_{R(n)}
\end{array}\right]
$$

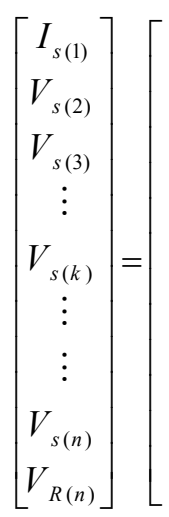

$$
\left[\begin{array}{c}
V_{s(1)} \\
0 \\
\vdots \\
\vdots \\
I_{P D} \\
\vdots \\
\vdots \\
0 \\
I_{R(n)}
\end{array}\right]
$$

where: $[Y]$ is a $(n+1) \times(n+1)$ matrix. If matrix $[Y]$ is inverted and re-arranged, it is possible to get Eq. (13).

Hence, if the line-end voltage, the neutral-end current and the PD current are known all other voltages and currents can be calculated. 


\section{RLC Ladder Network}

A PD generated within a generator winding can have an associated frequency range between a few $\mathrm{kHz}$ to hundreds MHz Fig. 2 shows an RLC ladder network model [3].

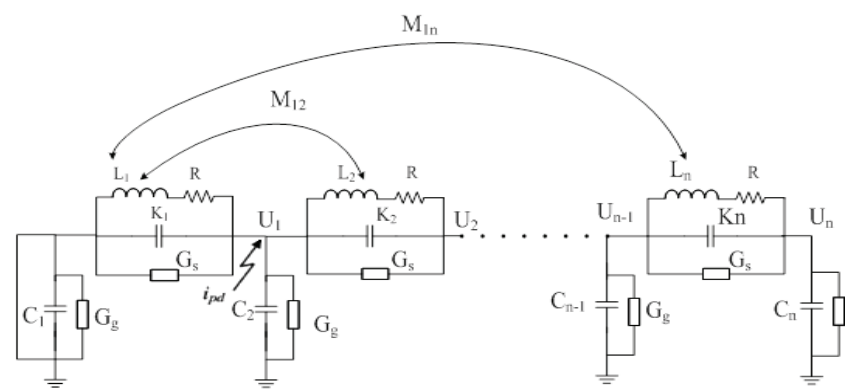

Fig. 2. RLC ladder network model for generator winding (PD occurs in node 2)

The PD occurrence can be simulated as a current pulse injected into the network. To obtain the output current through the neutral point in such a circuit, it is very convenient to use state-space equations as follows:

$$
\left\{\begin{array}{l}
x^{\circ}=A x+B u \\
y=C_{1} x+C_{2} x^{\circ}
\end{array}\right.
$$

with

$$
\begin{aligned}
& x=\left[i_{1}(t), i_{2}(t), \ldots, i_{N}(t), v_{1}(t), v_{2}(t), \ldots, v_{N}(t)\right]^{T} \\
& A=\left[\begin{array}{cc}
-L^{-1} R & -L^{-1} N \\
\Theta^{-1} M & \Theta^{-1} G
\end{array}\right] \\
& B=\left[\begin{array}{c}
0 \\
\Theta^{-1} K
\end{array}\right] \\
& C_{1}=\left[1,0, \ldots, 0,-G_{S}, 0, \ldots, 0\right] ; \\
& C_{2}=\left[0,0, \ldots, 0,-G_{S}, 0, \ldots, 0\right] \\
& K=\left[0, \ldots, 0,0, \ldots, 1_{(r)}, \ldots, 0\right]
\end{aligned}
$$

Note that the position of 1 in vector $K$ is decided by the input position. $L, \Theta$ and $G$ are the inductance, capacitance and admittance matrices of this system. The frequency response can be calculated by taking the Laplace transform of Eq. (14).

$$
\frac{Y(s)}{U(s)}=\left(C_{1}+C_{2} S\right)(S I-A)^{-1} B
$$

with regard to the unit distribution for the PD current source, the frequency spectrum of the system can be evaluated according the bellow equation:

$$
\begin{aligned}
& Y(s)=\left(C_{1}+C_{2} S\right)(S I-A)^{-1} B \\
& U(s) \approx 1
\end{aligned}
$$

In Eq. (16) only the matrix $B$ is related to the position of the PD current source location. The matrix $A$ is not affected by the position of the PD current source, also, the system structure does not affect by this discharge. Therefore, the poles of the system, which are the eigenvalues of the matrix $A$, are completely determined only by the system (matrix $A$ ). On the other hand the poles of frequency spectrum of the signal contain the information of the PD source location.

Based on the above theory, for the PD current detection and PD location, the three bellow steps will be down:

1. The frequency spectrum of $Y(s)$ has been calculated from PD current signal.

2. The poles of the system have been estimated from the frequency spectrum.

3. The location of PD source has been estimated from poles of the system.

Step 1 can be calculated easily through the use of a fast Fourier transform (FFT). The second step can be estimated from the transfer function of the winding model as following: [14-16]

$$
Y(S)=\frac{\beta(S)}{\alpha(S)}
$$

where $\alpha(S)$ and $\beta(S)$ are polynomials and defined by bellow:

$$
\begin{aligned}
& \alpha(S)=\alpha_{n} S^{n}+\alpha_{n-1} S^{n-1}+\ldots+\alpha_{1} S+\alpha_{0} \\
& \beta(S)=b_{m} S^{m}+b_{m-1} S^{m-1}+\ldots+b_{1} S+b_{0}
\end{aligned}
$$

applying Eqs. (18) and (19) in Eq. (17), the following equation is obtained:

$$
Y(S)=X(S) \times \theta
$$

where

$$
X(S)=\left[\begin{array}{llllll}
-S^{n} Y(S) & \ldots & -S Y(S) S^{m} & \ldots & S & 1
\end{array}\right]
$$

and

$$
\theta=\left[\begin{array}{lllllll}
\alpha_{n} & \ldots & \alpha_{1} & b_{m} & \ldots & b_{1} & b_{0}
\end{array}\right]
$$

After obtaining the coefficients, the poles of the system can be estimated from the roots of polynomial $\alpha(S)$. The third Step is a nonlinear optimization problem. The objective function is to minimize the difference between the eigenvalues of matrix $A$ and the calculated pole. The eigenvalues and pole frequencies to be arranged in descending ascending

$\operatorname{eig}(A)=\operatorname{eig}\left(\left[\begin{array}{cc}-L^{-1} R & -L^{-1} N \\ \Theta^{-1} M & \Theta^{-1} G\end{array}\right]\right)=\operatorname{poles}=\operatorname{roots}(\alpha(S))$ 
Finally, with the poles of the system, the location of the PD can be estimated

\section{Fast Transient Over-voltage's}

In this section the winding of generator has been modeled once using MTL and next with RLC ladder networks. Then the fast transient over-voltages have been computed between turns. The analysis was carried out for a $6 \mathrm{kV} / 250 \mathrm{~kW}$ test generator. Table 1 and 2 show the generator specification and coil parameters. At this paper the coil parameters have been evaluated from two methods, the first by using the COMSOL software and the geometry and custom shape of coils with FEM methodology and the second by measuring the parameters using conventional methods in the laboratory.

The results of the fast transient over-voltage between coils have been shown in the Figs. 3, 4 and 5 for measured MTL and RLC models respectively. This figures show the absolute value of voltage between coils with respect to applied input voltage.

\subsection{Pearson's correlation coefficient}

Correlation is a useful technique to investigate the

Table 1. Specification of the under the test generator

\begin{tabular}{c|c|c}
\hline Rated voltage & 6000 & $\mathrm{~V}$ \\
\hline Rated power & 250 & $\mathrm{~kW}$ \\
\hline Rated speed & 1500 & r.p.m \\
\hline Rated frequency & 50 & $\mathrm{~Hz}$ \\
\hline Winding Connection & star & --- \\
\hline Number of turns per phase & 176 & --- \\
\hline Number of coils per phase & 16 & --- \\
\hline Number of turns in a coil & 11 & --- \\
\hline Conductor dimensions & $11.5^{*} 236$ & $\mathrm{~mm}$ \\
\hline
\end{tabular}

Table 2. Parameters of the generator coils

\begin{tabular}{c|c|c|c|c}
\hline & $\mathrm{Li}(\mathrm{mH})$ & $\mathrm{R}(\Omega)$ & $\mathrm{Ki}(\mathrm{PF})$ & $\mathrm{Ci}(\mathrm{PF})$ \\
\hline Real & 17.2 & 0.35 & 30 & 1331 \\
\hline Estimated & 17.7 & 0.4 & 27.94 & 1253 \\
\hline
\end{tabular}

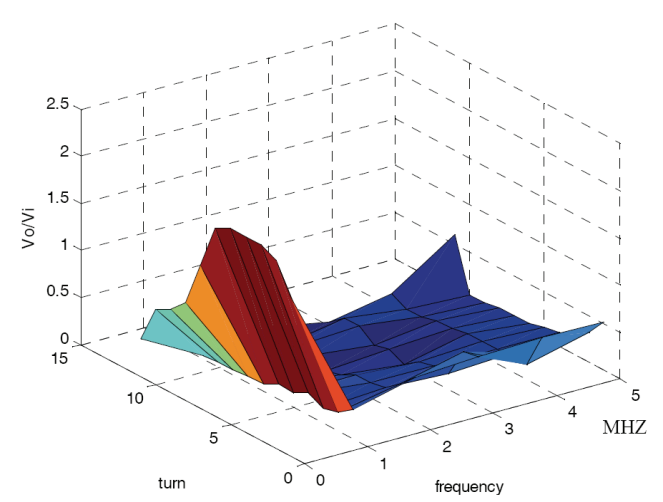

Fig. 3. Ratio of measured voltage to the applied input voltage $(10 \mathrm{kHz}<\mathrm{f}<5 \mathrm{MHz})$

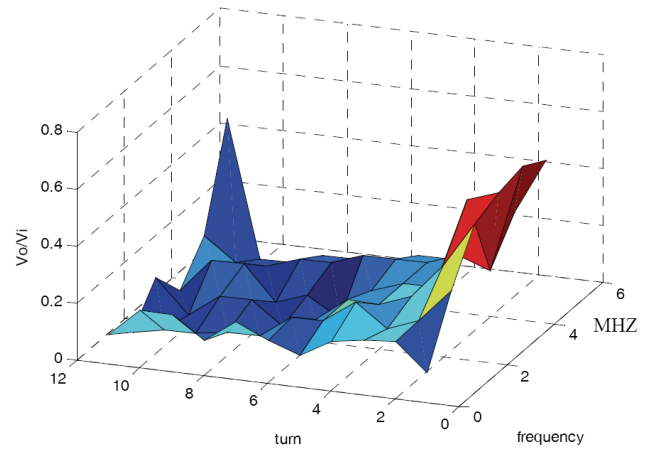

Fig. 4. Ratio of MTL model computed voltages to the applied input voltage $(10 \mathrm{kHz}<\mathrm{f}<5 \mathrm{MHz})$

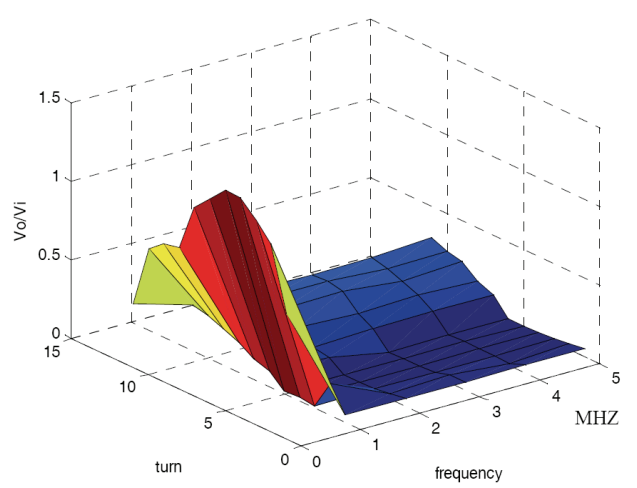

Fig. 5. Ratio of RLC ladder network model computed voltages to the applied input voltage $(10 \mathrm{kHz}<\mathrm{f}$ $<5 \mathrm{MHz}$ )

relationship between two quantitative, continuous variables. It measures the strength and direction of a linear relationship between two variables. This correlation coefficient is presented by the following equation:

$$
r=\frac{\sum_{i=1}^{n}\left(U_{m i}-\bar{U}_{m}\right)\left(U_{s i}-\bar{U}_{s}\right)}{\sqrt{\sum_{i=1}^{n}\left(U_{m i}-\bar{U}_{m}\right)^{2} \sum_{i=1}^{n}\left(U_{s i}-\bar{U}_{s}\right)^{2}}}
$$

where $U_{m}$ is the measured value of variable and $U_{s}$ is its simulated value. $r$ could be a number between 1 and -1 . A positive value of $\mathrm{r}$ means a positive linear relationship; a negative value of $r$ means a negative linear relationship. The correlation is ideal as approaches 1 and it is not desirable to approach -1[17]. Considering the measurement results shown in Fig. 4 and using SAS software to compute the correlation coefficient, the accuracy of the MTL and RLC ladder network model can be studied. Tables 3 and 4 show these coefficients for the RLC ladder network model and the MTL model simulations for respectively. These coefficients are the best means for evaluation of the models. Considering the last row of Table 3 it is obvious that the RLC ladder network model can present the best results for the frequency range of $10 \mathrm{kHz}<\mathrm{f}<1 \mathrm{MHz}$. The last row of Table 4 indicates that the MTL model can represent the 
Table 3. Pearson correlation coefficient for RLC ladder network and MTL model for $10 \mathrm{kHz}<\mathrm{f}<1 \mathrm{MHz}$

\begin{tabular}{c|c|c}
\hline Coil No. & RLC & MTL \\
\hline 1 & $\mathbf{0 . 2 6 1}$ & -0.171 \\
\hline 2 & $\mathbf{0 . 3 3 2}$ & -0.14 \\
\hline 3 & $\mathbf{0 . 2 4 7}$ & -0.108 \\
\hline 4 & $\mathbf{0 . 2 5}$ & 0.106 \\
\hline 5 & $\mathbf{0 . 2 5 7}$ & 0.101 \\
\hline 6 & $\mathbf{0 . 2 8 1}$ & 0.04 \\
\hline 7 & $\mathbf{0 . 2 8 4}$ & 0.48 \\
\hline 8 & $\mathbf{0 . 3 0 5}$ & 0.237 \\
\hline 9 & $\mathbf{0 . 3 2 9}$ & 0.197 \\
\hline 10 & $\mathbf{0 . 3 8 5}$ & 0.347 \\
\hline 11 & $\mathbf{0 . 5 3 4}$ & 0.421 \\
\hline AVR. & $\mathbf{0 . 3 1 5}$ & 0.105 \\
\hline
\end{tabular}

Table 4. Pearson correlation coefficient for RLC ladder network and MTL model for $1 \mathrm{MHz}<\mathrm{f}<5 \mathrm{MHz}$

\begin{tabular}{c|c|c}
\hline Coil No. & RLC & MTL \\
\hline 1 & -0.04 & $\mathbf{0 . 1 2 2}$ \\
\hline 2 & 0.022 & $\mathbf{0 . 4 0 2}$ \\
\hline 3 & -0.28 & $\mathbf{0 . 3 3 4}$ \\
\hline 4 & -0.093 & $\mathbf{0 . 3 0 3}$ \\
\hline 5 & -0.096 & $\mathbf{- 0 . 3 8 9}$ \\
\hline 6 & -0.1 & $\mathbf{0 . 4 2 6}$ \\
\hline 7 & 0.097 & $\mathbf{0 . 4 4 3}$ \\
\hline 8 & 0.034 & $\mathbf{- 0 . 0 2 6}$ \\
\hline 9 & -0.023 & $\mathbf{0 . 3 6 8}$ \\
\hline 10 & -0.133 & $\mathbf{0 . 3 4 4}$ \\
\hline 11 & -0.157 & $\mathbf{- 0 . 2 5 7}$ \\
\hline AVR. & -0.069 & $\mathbf{0 . 1 8 8}$ \\
\hline
\end{tabular}

response of generator better than next model for the frequency range of $1 \mathrm{MHz}<\mathrm{f}<5 \mathrm{MHz}$. The above-mentioned conclusions can be drawn from Figs. 3, 4 and 5 as well.

\section{Result of PD Localization}

In order to estimate the location of PD in generators with more reliability, it is better to verify the accuracy of the models that will be used in PD localization first. So it is recommended to measure and record the frequency spectrum of the generator in the first step. Then the simulation results must be compared with the measurements. If simulation results were satisfactory, the models can be used for PD localization. Otherwise the models must be modified or the parameters of the model must be optimized before PD localization.

At the first, PD pulses have been injected by the PD calibrator in the different part of the winding. Then the current signals measured/simulate in the end of the winding. These PD signals have been generated in $\mathrm{kHz}$ and $\mathrm{MHz}$ frequency range that used for RLC ladder network and MTL models respectively. Fig. 6 shows the PD pulse studies circuit in a laboratory. The PD pulse to be generated in the $\mathrm{kHz}$ range has been shown in Fig. 7. Figs. 8, 9 show the comparison between the current

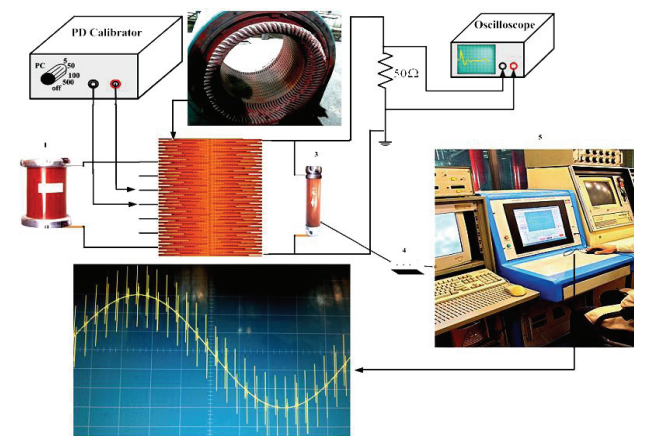

Fig. 6. PD pulse measured in circuit in a laboratory

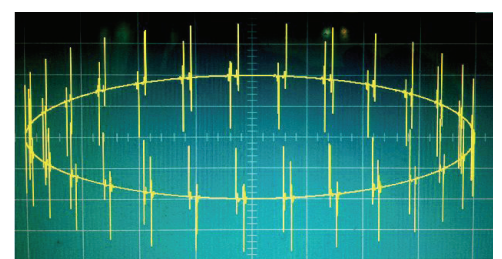

Fig. 7. The PD pulses measured in the $\mathrm{kHz}$ range (the PD has been injected in node 6)

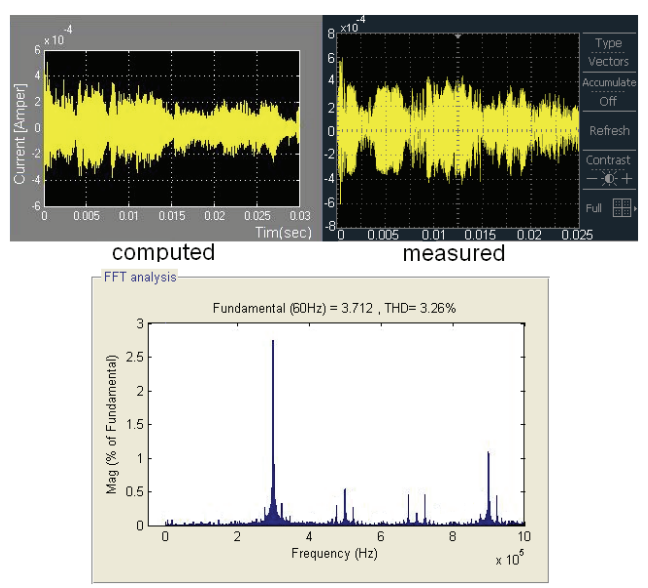

Fig. 8. The comparison of current and the spectrum (PD has been injected in node 1 for RLC ladder network model)

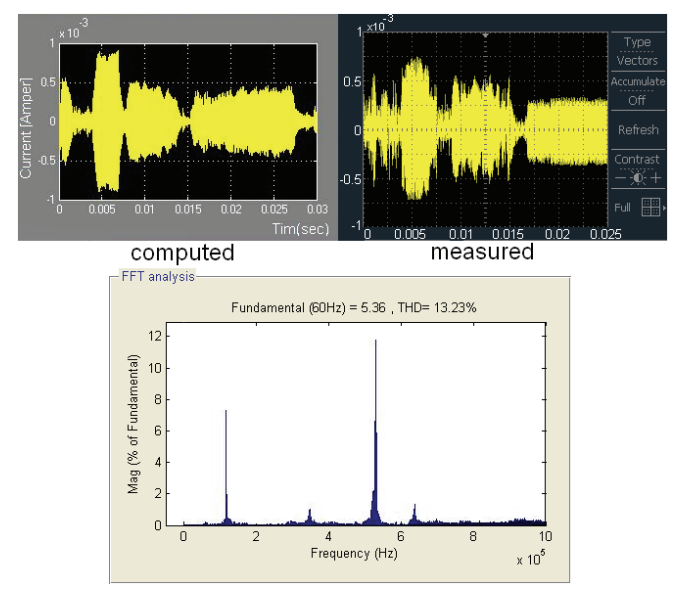

Fig. 9. The comparison of current and the spectrum (PD has been injected in node 6 for RLC ladder network model) 
spectrum for RLC model and measurements results. The $\mathrm{PD}$ pulse to be generated in the $\mathrm{MHz}$ range has been shown in Fig. 10. The Figs. 11, 12 show the comparison between the current spectrum for MTL simulated model and measurements results.

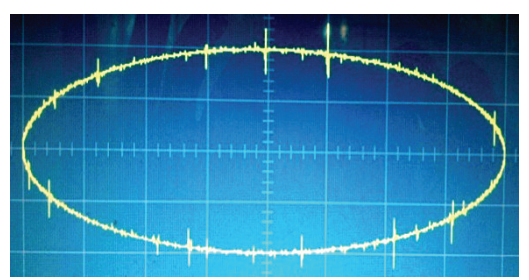

Fig.10. The PD pulses measured in the $\mathrm{MHz}$ range (the PD has been injected in node 6)

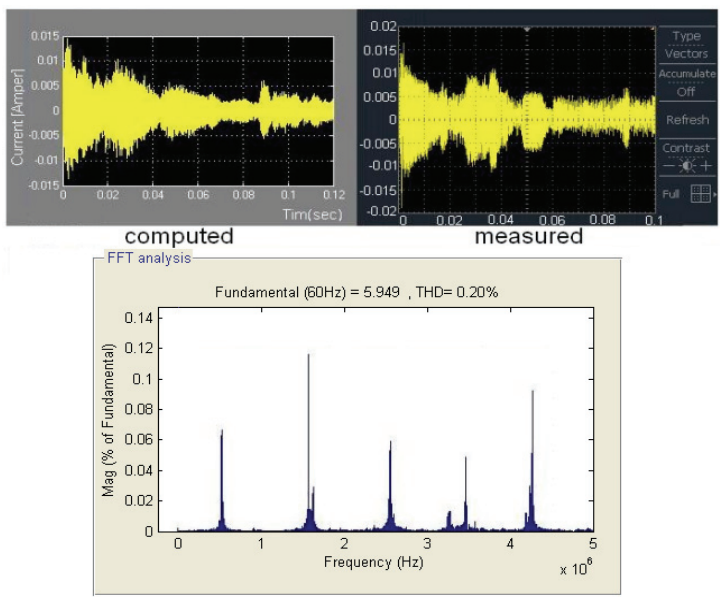

Fig. 11. The comparison of current and the spectrum (PD has been injected in node 1 for MTL model)

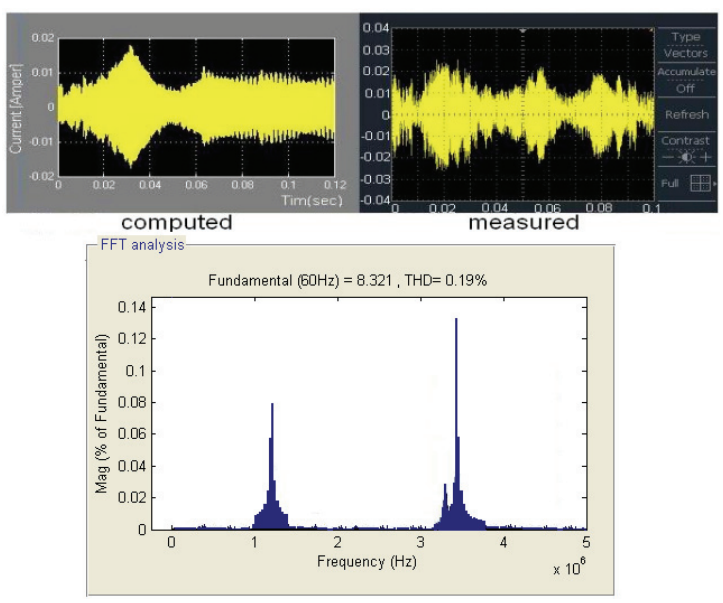

Fig. 12. The comparison of current and the spectrum (PD has been injected in node 6 for MTL model)

Table 5. Comparison between real position and the simulation estimated position of PD

\begin{tabular}{c|c|c|c}
\hline Real position & $\mathrm{PD}(10)$ & $\mathrm{PD}(6)$ & $\mathrm{PD}(1)$ \\
\hline Estimated (RLC) & 11 & 6 & 2 \\
\hline Estimated (MTL) & 10 & 6 & 2 \\
\hline
\end{tabular}

In this section from the frequency spectrum of the current signals, and poles estimate of the system, the location of PD can be estimated along the winding. Then these results compared with real position. Table 5 shows the comparison between the real position and the simulated estimated position of PD (Depending to the node).

\section{Conclusion}

This paper compared the measurement and simulation results of transient over voltages and then partial discharge localization in the windings of a $6 \mathrm{kV} / 250 \mathrm{~kW}$ generator. Voltages along the generator windings were simulated by applying MTL and RLC ladder network theory. The results of the transients voltage calculated in the coils of the winding were compared with laboratory measurement. A relatively good correlation observed between measurement and RLC Ladder Network model simulation results for the frequency range of $10 \mathrm{kHz}<\mathrm{f}<1 \mathrm{MHz}$. However in the range of the frequency $1 \mathrm{MHz}<\mathrm{f}<5 \mathrm{MHz}$, the MTL model, provides a better agreement between the simulated and the measured voltages.

An algorithm for partial discharge localization has been developed in this paper. The approach is based upon frequency spectrum analysis of PD current signals. PD pulses have been injected by the PD calibrator in the different part of the winding. Then the PD signals measured or simulate in the end of the winding. These PD signals have been generated in $\mathrm{kHz}$ and $\mathrm{MHz}$ frequency range that used for RLC ladder network and MTL models respectively. A relatively good correlation have been observed between measurement and RLC ladder network model simulation results for the frequency range of $\mathrm{kHz}$ $(10 \mathrm{kHz}<\mathrm{f}<1 \mathrm{MHz})$, however in the frequency range of $\mathrm{MHz}(1 \mathrm{MHz}<\mathrm{f}<5 \mathrm{MHz})$, the MTL model have been provided the better agreement between the simulated and the measured for PD Location.

\section{References}

[1] R. Rudenderg, "Performance of travelling waves in coils and windings," AIEE Trans., pp. 1031-1045, 1940.

[2] P. I. Fergastad and T. Henriksen, "A calculation method for impulse voltage distribution and transferred voltage in transformer windings," IEEE Trans. Power APP. \& SYS., vol. 97, no. 3, pp. 930-939, May. 1978.

[3] T. J. Lewis, "The transient behavior of ladder networks of the type representing machine and transformer windings'," in Proceedings of IEEE PES, 101, Pt.2, pp.541-553, 1954.

[4] K. Cornic, B. Filliat, C. Kieny, and W. Muller, "Distribution of very fast transient overvoltages in 
transformer," in Proceedings of CIGRE, pp. 12-234, 1992.

[5] K. L. Christiansen, and A. Pedersen, “'Transient surges and motor protection'," in Proceedings of IEEE PES Proceedings of the electrical insulation conference, 68C6-EI-87, pp. 148-50, 1968.

[6] R. L. Nailen, "'Transient surges and motor protection'," in Proceedings of IEEE PES Industrial and commercial power system technical conference, Seatel, USA, May 1979.

[7] W. T. Weeks, 'Multiconductor transmission-line theory in the TEM approximation: IBM J. Res. \& Dev, 1972.

[8] M. Popov, v. sluis, R.P.P.smeets, "complete analysis of very fast transients in layer-type transformer windings," International Conference on Power Systems Transients, Lyon, France, June 2007.

[9] K. J. Kornic and T. R. Thompson, "'Steep-fronted switching voltage transients and their distribution in motor windings, Part 2." in Proceedings of IEE Proc Electro. Power Application, pp. 56-63, 1982.

[10] M. Popov, L. V. Sluis, and G. C. Paap, "Computation of very fast transient over voltages in transformer windings," IEEE Trans. Power Delivery, vol.18, no.4, pp.1268-1274, Oct. 2003.

[11] A. K Agrawal and H. M. Fowles, "Application of modal analysis to the transient response of multiconductor transmission lines with branches," IEEE Trans. EMC, pp.256-262, 979.

[12] G. N. Petrove., and A. I. Abromov, 'Overvoltage stresses in the turn insulation of electrical machinery windings during electromagnetic transients: Electrichestov, 1954, p.24-31.

[13] P. J. Mclaren and H. Oraee, "Multi-conductor transmission line model for the line end coil of large AC machines," in Proceedings of IEEE Conference, pp. 149-156, 1985.

[14] H. G. Sedding, "The partial discharge calibration problem in rotating machines," in Proceedings of IEEE Winter power meeting Panel session 92 TH0425 9PWR, pp. 24-28, 1992.

[15] P. G. Mclaren and M. AbdelRahman, "Modeling of large AC motor disk for steep-fronted surge studies," IEEE Trans. Ind. Appl., vol. 24, no. 3, pp. 422-426, 1988.

[16] I. J. Kemp and G. C. Stone, "Calibration difficulties associated with partial discharge detectors in rotating machine applications," Proceedings of 18th conference on Electrical and electronic insulation, Chicago, USA, pp. 92-97, 1978.

[17] SAS/STAT Users Guide ver. 6: 4th ed., vol. 2. Cary, CA, SAS Institute, Inc., 1990d.

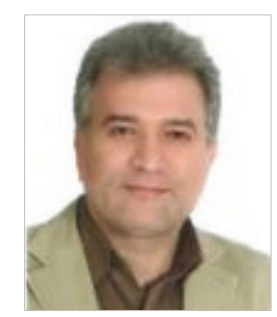

S. M. Hassan Hosseini was born in Tehran, in 1969. He received the B.Sc degree in electrical power engineering from Mashhad Ferdowsi University, Mashhad, Iran in 1993. He received the M.Sc and Ph.D degrees in electrical power engineering in 2000 and 2005 from Islamic Azad University SouthTehran Branch and Science \& Research Branch, Tehran, Iran, respectively. His research interest is transient modeling of transformers and generators, Partial Discharge, High Voltage Engineering.

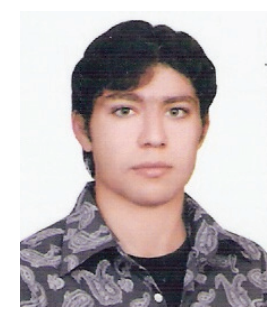

S. M. Hosseini Bafghi was born in Bafgh, Iran, in 1986. He received the B.Sc. and M.SC degrees in electrical power engineering from Islamic Azad University of Mehriz and South Tehran Branch in 2009 and 2013 respectively. Since 2011, He joined as a lecturer of Electrical Engineering Department, Faculty of Engineering Islamic Azad University Bafgh Branch. His research interest is transient and PD modeling of Generators. 